\title{
PRODUCT RE-DESIGNING AND DEVELOPMENT OF KEY DUPLICATING MACHINE - A CASE STUDY
}

\author{
Deshpande A.S. ${ }^{1}$, Chate U.N. ${ }^{2}$, Vinayak Malik ${ }^{3}$ \\ ${ }^{1}$ Fr.C.Rodrigues College of Engineering, Mumbai, India \\ ${ }^{2,3}$ Department of Industrial and Production Engineering, Gogte Institute of Technology, Belgaum, India \\ E-mail: ${ }^{1}$ asd@fragnel.ac.in
}

\begin{abstract}
In this era of stiff competition the economic success of manufacturing firms depends on their ability to identify the needs of customers and to quickly create products that meet these needs and can be produced at low cost. Achieving these goals is not solely a design problem or a manufacturing problem; it is a product development problem involving all of these functions. The present work is carried out in a manufacturing unit, developing industrial products. In its product range the company involves the manufacture of key duplicating machine on small basis and this machine required improvement to survive in competitive market (key making). The paper highlights how the product development techniques are applied in improving the key duplicating machine effectively and efficiently. The present paper discuses about the re-designing and improvements in the product performance. The work was further extended for developing a revised product with better features. The scope of work involves extensive survey of users and design options available. The significant aspect of the present work is that, the theoretical concepts involved in product development have been realized with a practical perspective. The work has been realized by incorporating these improvements in the product. The work is supported by digital prototyping of the model using CAD modeler.
\end{abstract}

Key words: Product Development, Performance, re-designing.

\section{INTRODUCTION AND GENERAL BACKGROUND}

There is a great demand for key duplication in market. The conventional method of making duplicate of a key is by using files and bench vice. The original key and the new key blank of its shape are held in vice, set properly and the required profile is generated using files. This process requires a lot of efforts, time and personnel skill.

In the recent time the key duplicating work is made easier, quicker and without much efforts by the use of key duplicating machines. One of such machines is manufactured by Tool Holders Pvt. Ltd at Belgaum. As per the needs of customers and to meet the new changes in market of key making the machine required improvement. To solve this problem, the machine was developed, by following a structured product development process. Fig. 1 shows the picture of existing model of key duplicating machine, which has to be improved.

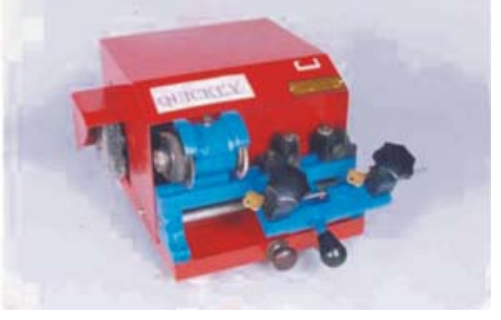

Fig. 1. Existing model of key duplicating machine

\section{PRODUCT DEVELOPMENT METHODOLOGY APPLIED FOR KEY DUPLICATING MACHINE IMPROVEMENT}

A product is something sold by an enterprise to its customers. Product development is the set of activities beginning with the perception of a market opportunity and ending in the production, sale and delivery of a product.

Few products are developed by a single individual and the current case of key duplicating machine is a good example of this. To improve the key duplicating machine a structured product development methodology is used, which contains the following steps

w Product planning

w Concept development

a) Identifying customer needs

b) Establishing target specification

c) Concept generation

d) Concept selection

e) Concept testing

f) Establishing final specification

w Re-design of key duplicating machine 
In this section, how product development steps are applied in the current case of key duplicating machine improvement is discussed. The product planning process takes place before a product development project is formally approved, before substantial resources are applied.

Since the key duplicating machine development project is carried out individually there is no task to be performed for forming a product development team. In the current project of key duplicating machine development, there was not much work involved to decide which product has to be developed, since it was already asked to make improvements in key duplicating machine. So the next step in product planning phase was to make a mission statement for the current project. But before preparing the mission statement for key duplicating machine project lets have a brief idea about the types of development project.

\section{TYPES OF PRODUCT DEVELOPMENT PROJECTS}

Product development projects can be classified as four types:

w New product platforms: These types of project involve a major development effort to create a new family of products based on a new, common platform. The new product family would address familiar markets and product categories.

w Derivatives of existing product platforms: These projects extend an existing product platform to better address familiar markets with one or more new products.

w Incremental improvements to existing products: These projects involve adding or modifying some features of existing products in order to keep the product line current and competitive.

w Fundamentally new products: These projects involve radically different product or production technologies and may help to address new and unfamiliar markets. Such projects inherently involve more risk; however, the long-term success of the enterprise may depend on what is learned through these important projects.

The current key duplicating machine development project comes under the category of Incremental improvement to existing products. Table 1 shows the mission statement for the key duplicating machine development project. Mission Statement summarizes the direction to be followed during the product development and it helps in guiding as the development process progresses.
Table 1. Mission Statement for key duplicating machine project

\begin{tabular}{|c|c|}
\hline \multicolumn{2}{|c|}{$\begin{array}{l}\text { Mission Statement } \\
\text { Key duplicating machine cutting considerable variety of keys providing more business } \\
\text { to key duplicators }\end{array}$} \\
\hline \begin{tabular}{|l|} 
Product Description \\
\end{tabular} & Produces duplicates of original keys \\
\hline Key Business Goals & $\begin{array}{l}\text { - Supporting Cost leadership and Customer focus strategy } \\
\text { - Increase the sales by } 25 \% \\
\text { - Environmentally friendly }\end{array}$ \\
\hline Primary Market & $\begin{array}{l}\text { - Non-professional key making } \\
\text { (Unskilled users in key making) }\end{array}$ \\
\hline Secondary Market & $\begin{array}{l}\text { Professional key Making } \\
\text { (Highly skilled users in key making) }\end{array}$ \\
\hline \begin{tabular}{|l} 
Assumptions and \\
Constraints
\end{tabular} & $\begin{array}{l}\text { - Incremental improvements to existing product } \\
\text { - Copying mechanism purely based on mechanical } \\
\text { engineering solutions } \\
\text { - Entire manufacturing of machine in local area }\end{array}$ \\
\hline Stake Holders & $\begin{array}{l}\text { - End users } \\
\text { - Locks manufacturing industries } \\
\text { - Production or Manufacturing Department } \\
\text { - Cervice Department }\end{array}$ \\
\hline
\end{tabular}

\section{TYPES OF KEYS}

A survey and brief study was made to identify the varieties of keys in key making market during this phase itself. Following are the major varieties of keys available in market, and that specially come for duplication purpose. These keys can be divided into two broad categories, that is

w Domestic keys

w Automobile keys

Domestic keys

Table 2. Kind of problem and Percentage of different types of keys(Domestic)

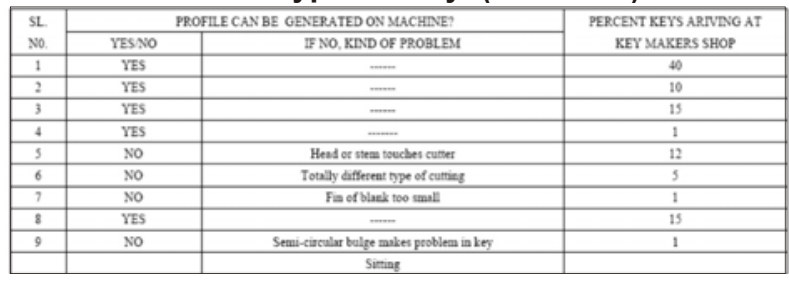

Table 2 shows which type of domestic keys cannot be duplicated on the existing machine, and the reasons for the same. It also shows the percentage of different types of keys that come for duplication purpose at key maker shop. The Table 3 helps in understanding which portion of the keys that currently cannot be duplicated on the existing machine should be given the most importance. It can be observed that long keys is an area which has to be taken care of, since these are the keys that come frequently at key makers shop for duplication purpose and which cannot be duplicated in the existing model of key duplicating machine. 


\section{Automobile keys}

Table 3. Kind of problem and Percentage of different types of keys (Automobile)

\begin{tabular}{|c|c|c|c|}
\hline \multirow{2}{*}{$\begin{array}{l}\text { SL. } \\
\text { No. }\end{array}$} & \multicolumn{2}{|c|}{$\begin{array}{l}\text { PROFILE CAN BE } \\
\text { GENERATED ON MACHINE? }\end{array}$} & \multirow{2}{*}{$\begin{array}{l}\text { PERCENT KEYS ARIVING AT } \\
\text { KEY MAKERS SHOP }\end{array}$} \\
\hline & YESNO & IF NO, KLND OF PROBLEM & \\
\hline 1 & YES & $\ldots$ & 50 \\
\hline 2 & YES & $\ldots$ & 47 \\
\hline 3 & No & Totally differeet kind of curring & 1 \\
\hline 4 & No & Totally different kind of curring & 2 \\
\hline 5 & No & Tothly different kind of curting & 0 \\
\hline
\end{tabular}

Table 3 shows which type of automobile keys cannot be duplicated on the existing machine, and the reasons for the same. It also shows the percentage for different types of keys that come for duplication purpose at key maker shop. From the Table 3 it can be observed that in case of duplicating variety of automobile keys, the existing machine is satisfying to a good extent.

\section{CONCEPT DEVELOPMENT 1) IDENTIFYING CUSTOMER NEEDS}

This phase presents a method for comprehensively identifying a set of customer needs. The goals of the method are to:

w Ensure that the key duplicating machine is focused on customer needs

w Provide a fact base for justifying the key duplicating machine specifications

w Create an archival record of the needs activity of the development process

w Ensure that no critical customer need is missed or forgotten

General steps that come under identifying customer need activity are

w Gathering the raw data from customers

w Interpreting the raw data in terms of customer needs

w Establishing the relative importance of the needs

Templates were prepared during identifying the customer needs phase for key duplicating machine. The template was filled in soon after the interaction with the customer and edited. Many customers were interviewed and templates were prepared.

A scale from 1 to 5 was used as shown below to indicate importance of the feature, to give the importance weighting to the needs collected from the key makers.

Scale from 1 to 5 indicating how important the feature is

1. Feature is undesirable, I would not consider a product with this feature.
2. Feature is not important, but I would not mind having it.

3. Feature would be nice to have, but is not necessary.

4. Feature is highly desirable, but I would consider a product without it.

5. Feature is critical, I would not consider a product without this feature

Table 4. Customer needs for the key duplicating machine and their relative importance

\begin{tabular}{|c|c|c|}
\hline SL No. & Need & Importance \\
\hline 1 & $\begin{array}{l}\text { The } U \text { cutter of key duplicating machine } \\
\text { gives better life }\end{array}$ & 5 \\
\hline 2 & $\begin{array}{l}\text { Key duplicating machine makes all the variety } \\
\text { of keys }\end{array}$ & 4 \\
\hline 3 & $\begin{array}{l}\text { Key duplicating machine rums smoothly withoet } \\
\text { making noise }\end{array}$ & 3 \\
\hline 4 & $\begin{array}{l}\text { Key duplicating machine makes keys with } \\
\text { better finish }\end{array}$ & 3 \\
\hline 5 & $\begin{array}{l}\text { Key duplicating machise avoids chips of metal } \\
\text { from going into eyes while cutting key }\end{array}$ & 5 \\
\hline 6 & $\begin{array}{l}\text { Key duplicating machine cut grooves in special } \\
\text { Shuter lock keys }\end{array}$ & 3 \\
\hline 7 & Key duplicating machine is light weight & 3 \\
\hline 8 & $\begin{array}{l}\text { Key duplicating machine can duplicate the keys } \\
\text { in the absence of electricity }\end{array}$ & 3 \\
\hline 9 & $\begin{array}{l}\text { The key and its type of blank setting in the vice } \\
\text { is better in key duplicating machise }\end{array}$ & 4 \\
\hline 10 & Key duplicating machine gives a pleasing look. & 3 \\
\hline 11 & $\begin{array}{l}\text { Key duplicating machine is purchasable } \\
\text { compared to the fentures provided by it and } \\
\text { elements used in it }\end{array}$ & 4 \\
\hline 12 & $\begin{array}{l}\text { Key duplicating machine cuts the keys } \\
\text { Automatically }\end{array}$ & 1 \\
\hline
\end{tabular}

Table 4 shows customer needs for the key duplicating machine and their relative importance shown in a convenient spreadsheet format.

\section{ESTABLISHING TARGET SPECIFICATIONS}

Customer needs are generally expressed in the "language of the customer". However, while such expressions are helpful in developing a clear sense of the issues of interest to customers, they provide little specific guidance about how to design and engineer the key duplicating machine. They simply leave too much margin for subjective interpretation. For this reason, specifications were established, which spell out in precise, measurable detail what the key duplicating machine has to do, what is to be attempted to achieve in order to satisfy the customer needs.

The target specifications are established after the customer needs have been identified but before product concepts have been generated and the most promising one selected. The process of establishing the target specifications contains following steps,

w Preparation of list of metrics, using the needs-metrics matrix, if necessary 


\section{w Collecting competitive benchmarking information}

w Setting ideal and marginally acceptable target values for each metric

The need that the key duplicating machine gives a pleasing look may be quite critical to success in the fashion-conscious key duplicating machine market, but how can pleasing look be quantified? In these cases, the need statement has to be simply repeated as a specification and this metric will be subjective and was evaluated by a panel of customers. Some metrics will not lend themselves to numerical values. This is entered as "List" in units column. In table 8 it can be observed that for Metric No. 2 cutter, 'list' word is entered in units column. The cutter is selected from the following list of cutters available that is H.S.S (Straight teeth or Staggered teeth) cutter, Solid Tungsten Carbide Cutter, Carbide Tipped Cutter, Titanium Nitride Coated Cutter (Straight teeth or Staggered teeth). Here Cutter refers to Metal Slitting Saws.

Table 5. List of metrics for key duplicating machine

\begin{tabular}{|c|c|c|c|c||}
\hline \hline Metric No & Need No & Metric & Importance & Units \\
\hline 1 & $1,2,3,4$ & Variable cutring speed & 5 & M/min \\
\hline 2 & $2,3,4$ & Cutter & 3 & list \\
\hline 3 & 3 & Sound level & 3 & $\mathrm{db}$ \\
\hline 4 & 11 & Unit manufacturing cost & 4 & $\mathrm{Rs}$ \\
\hline 5 & 7 & Total mass & 3 & $\mathrm{Kg}$ \\
\hline 6 & 10 & Pleasing look & 3 & subj \\
\hline 7 & 6 & $\begin{array}{c}\text { Bi-directional vertical travel for } \\
\text { Carriage }\end{array}$ & 3 & $\mathrm{~mm}$ \\
\hline 8 & 5 & Carter cover size & 5 & $\mathrm{~mm}$ \\
\hline 9 & 8,12 & Power & 3 & $\mathrm{kw}$ \\
\hline 10 & 9 & Setter body height & 4 & $\mathrm{~mm}$ \\
\hline 11 & 2 & $\begin{array}{c}\text { Key cutting capacity in terms of } \\
\text { Vaniety }\end{array}$ & 4 & $\%$ \\
\hline \hline
\end{tabular}

Table 5 shows the list of metrics for the key duplicating machine. The relative importance of each metric and the units for the metric are also shown.

Table 6 shows the Need-Metric Matrix representing the relationship between the Needs and Metrics for key duplicating machine project. The relationship of the new product to competitive products is paramount in determining commercial success. For the current project, the competitive benchmarking is done by observing the competitors product in use at customers site who are using these machines, and also competitive benchmarking information was got through mediums like internet, industrial journals, magazines etc. A competitive benchmarking chart was constructed with rows corresponding to the customer needs and columns corresponding to the competitive products
Table 6. The Need-Metric Matrix

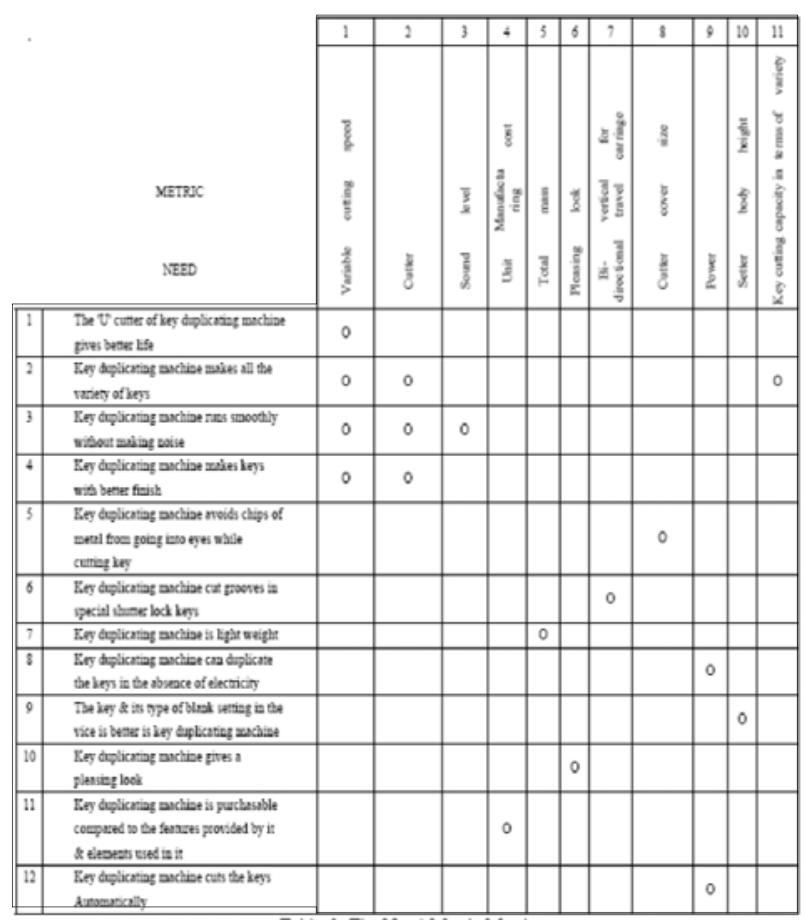

The available information is synthesized in order to actually set the target values for the metrics. Two types of target values are useful, ideal value and a marginally acceptable value. The ideal value is the best result that could be hoped for. The marginally acceptable value is the value of the metric that would just barely make the product commercially viable. Both of these targets are useful in guiding the subsequent stages of concept generation and concept selection, and for refining the specifications after the product concept has been selected.

Table 7. Target specifications

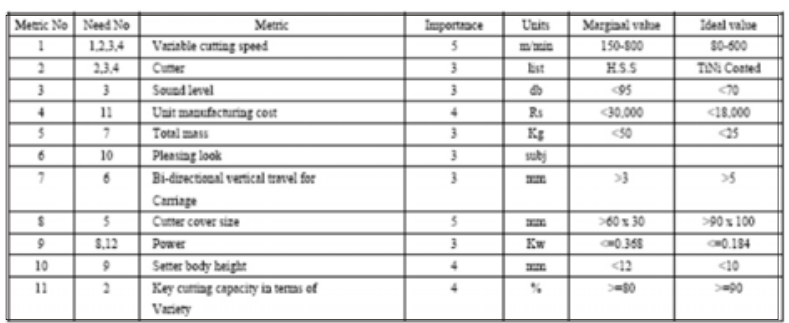

Table 7 shows the marginal and ideal values for the list of metrics of key duplicating machine, these values are fixed before the concept generation stage and these may be refined after a particular concept is finalized for key duplicating machine. 


\section{CONCEPT GENERATION}

A product concept is an approximate description of the technology, working principles, and form of the product. The degree to which a product satisfies customers and can be successfully commercialized depends to a large measure on the quality of the underlying concept. A concept is expressed as a sketch and is accompanied by a brief textual description. In the present case of key duplicating machine improvement 10 concepts were generated. To develop concepts for key duplicating machine external and internal search were conducted.

Charts containing description regarding each concept, and the salient features of each concept were also prepared, which guides in selecting the particular concept for key duplicating machine development project. Since it is an incremental improvement kind of project different concepts in the form of different kinds of mechanism to give feed are proposed.

\section{CONCEPT SELECTION}

Concept selection is the process of evaluating concepts with respect to customer needs and other criteria, comparing the relative strengths and weakness of the concepts, and selecting one or more concepts for further investigation or development. Decision techniques employed for selecting concepts range form intuitive approaches to structured methods. One of such structured approach is concept scoring method which is used in present case of key duplicating machine.

Concept scoring uses a reference concept to evaluate concept variants against selection criteria. Concept scoring uses weighted selection criteria and a finer rating scale. The selection criteria are listed along the left hand side of the screening matrix as shown in Table 14. These criteria were chosen based on the customer needs that have been identified, as well as on the needs of the enterprise. In the current case of key duplicating machine improvement the existing model of the machine is taken as the reference itself. In key duplicating machine project, 10 concepts were proposed, after discussions 3 concepts were selected for evaluation.

Table 9 illustrates the scoring matrix used in this stage. The concepts which have been identified for analysis are entered on the top of the matrix. After the criteria are entered, importance weights were added to the matrix. To distinguish among competing concepts, a finer scale was used as shown in Table 8.
Table 8. A finer scale

\begin{tabular}{|l|c|}
\hline \multicolumn{1}{|c|}{ Relative performance } & Rating \\
\hline Much worse than reference & 1 \\
\hline Worse than reference & 2 \\
\hline Same as reference & 3 \\
\hline Better than reference & 4 \\
\hline Much better than reference & 5 \\
\hline
\end{tabular}

After entering the ratings, weighted scores were calculated by multiplying the raw scores by the criteria weights. The total score for each concept is the sum of the weighted scores. Finally, each concept was given a rank corresponding to its total score, as shown in Table 14. Based on the selection matrix, it was decided which concept or concepts to select. Table 14 shows the concept scoring method applied to key duplicating machine. From the table it can be observed that the Nut and Screw Mechanism with Spring Arrangement is finally selected for further development.Fig. 2 shows the line sketch of Nut and Screw Mechanism with Spring Arrangement, which was finalized in concept selection stage.

\section{Table 9. The Concept Scoring Matrix}
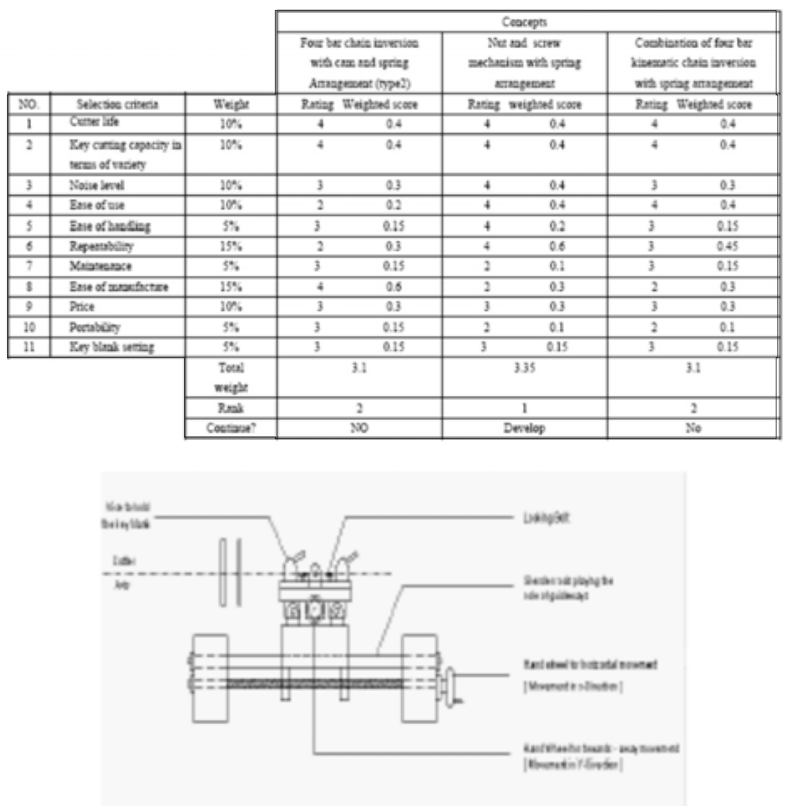

Fig. 2. Nut and Screw Mechanism with Spring Arrangement 


\section{CONCEPT TESTING}

In concept testing basically the concepts were communicated to the end users so that the responses from the users, guide in further development for the product. Concepts were tested to verify that the customer needs have been met, and identifying any shortcomings, which can be remedied during further development.

The concept, which was selected in concept selection stage, that is nut and screw mechanism with spring arrangement, was communicated to customers (key makers) by means of verbal descriptions and line sketches and their responses were fairly positive. But since it is an iterative process 3D computer model of key duplicating machine and its color pictures based on the selected concept were shown after modeling procedure was over.

\section{RESULTS AND DISCUSSION}

When the new product is an incremental improvement on an existing product concept, then the product architecture is defined within the product concept. This is because, the basic technologies and working principles of the product are predefined, and so conceptual design efforts are generally focused on better ways to embody the given concept. That's why the system-level design and detailed design stages get eliminated in the current case of key duplicating machine improvement project. Since key duplicating machine development is an incremental improvement kind of project, most of the parts remain the same, which are used, in existing model of key duplicating machine. To get a basic idea about the dimensions of the parts that are modified, revised, changed in the new model of key duplicating machine brief design calculations were done. The design data cannot be displayed due to the confidential reasons. The components were analyzed on 3D CAD modeler.

The variable cutting speed is achieved by using a variable speed DC motor. The motor is a normal single speed permanent magnet motor, but variable speed is got by attaching an electric drive unit to it. The speed is varied by controlling the voltage to motor with the help of electric drive unit. Though other options were available to get a variable speed for example, stepped pulley and speed change gearbox used as in lathe, the electrical step less regulation of speed was chosen. The decision was guided by the following reasons

g) Safety and convenience for control while speed changing

क) Fatigueless speed changing activity 3s Possibility of carrying out key cutting operations at optimum cutting speed. This not only increases productivity, but also increases tool life.

bs Noiseless and more smooth rotation and absence of jerks which are characteristic of geared drive

Two parallel springs are used in the mechanism, to guide the cutting action, while cutting automobile keys, so that automobile keys can be cut at a single pass of carriage, making automobile key cutting operation more simple than earlier. This logic of spring force application was captured during competitive benchmarking of the product (silica key duplicating machine). The springs are disengaged or locked using locking pins while cutting domestic keys.

To enhance the key cutting capacity in terms of variety, the concept of cutter position interchange thereby changing the layout of keys was introduced, along with linear dimensional changes between the two vices and between the cutters and the respective copy dogs, so that long keys can be accommodated.

Fig. 3 shows the picture of new model of key duplicating machine modeled in SolidWorks CAD package. It gives an idea, a view that how a key duplicating machine looks like with newly applied concept.

Fig. 4 shows the picture of improved version of existing model of key duplicating machine (model 2), modeled in SolidWorks CAD package. It shows how the machine looks like after making some incremental changes.

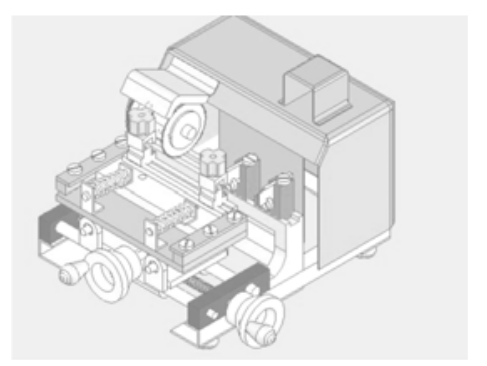

Fig. 3. Re-designed and developed new model [Model 1]

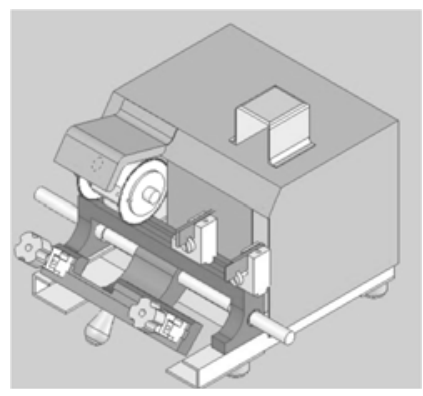

Fig. 4. Improved version of existing key duplicating machine [Model 2] 
A suitable cutter cover of size $80 \times 95 \mathrm{~mm}$ is made to avoid chips of metal from entering into eyes while key cutting.

All the above solutions are applied to the existing model of key duplicating machine

except the spring force application solution to get the new improved version of the machine (model 2). Also other changes like suitable color combination that is golden yellow and white, and cover of drive are done for improved model of key duplicating machine (model 2).

\section{CONCLUSION}

Few of the challenging aspects covered in the present work were as follows,

w Understanding and applying a structured product development technique to key duplicating machine which is helpful in developing any type of complex or simple products effectively and efficiently.

w Conducting the market survey and intervening the customers (key makers) at the key duplicating machine use site in a systematic step by step process to create a high quality information channel that runs directly between customers in target market and the developers of the key duplicating machine to best experience the use environment of the product, the data recorded is helpful for future development of the key duplicating machine.

w The solutions got from the structured product development process, were applied to the existing model of key duplicating machine to get an improved version of key duplicating machine (model 2) and constructing its pre-production version and also a new model (model 1) of key duplicating machine was developed.

w An improved version of existing model of key duplicating machine, which provided the following advantages to key makers

21

Steel keys (steel with tensile strength of $82 \mathrm{~kg} / \mathrm{sq}$ $\mathrm{mm}$ ) can be cut

कs

Long keys (up to $18 \mathrm{cms}$ ) can be duplicated

g)

Long steel keys (steel with tensile strength of 82 $\mathrm{kg} / \mathrm{sq} \mathrm{mm}$ ) can be duplicated in much lesser time that is in 5 minutes compared to earlier which would require 30 minutes using files, and which was not possible to duplicate in existing model of key duplicating machine

bs Improved life of 'U' cutter (improved by 60\%)
2)

More business to the key makers, as on the improved version of the existing model of key duplicating machine $90 \%$ of the keys can be cut, compared to the existing model of key duplicating machine on which $80 \%$ of keys can be cut.

\section{ACKNOWLEDGEMENT}

Authors express their sincere thanks to Mr.Deelip Bhagwat, an expert entrepreneur from Belgaum for suggesting the problem and helping all through.

\section{REFERENCES}

[1] Karl T. Ulrich And Steven D. Eppinger 'Product Design And Development', Published By Mcgraw-Hill Companies, 1995

[2] A.K.Chitale. R.C.Gupta 'Product Design And Manufacturing' Published By Prentice-Hall Of India Pvt. Ltd., Second Edition,2002

[3] P.L.Ballaney 'Theory Of Machines' Khana Publishers, Sixteenth Edition,1988

[4] Cmti 'Machine Tool Design Handbook' Tata Mcgraw-Hill Publishing Company Limited,1982

[5] N.K.Mehta 'Machine Tool Design' Tata Mcgraw Hill Publishing Company Limited, 1995

[6] S.K.Hajra Choudhury, S.K.Bose,A.K.Hajra Choudhury And Nirjhar Roy, 'Elements Of Workshop Technology Vol li Machine Tools', Media Promoters And Publishers Pvt. Ltd., First Edition, 1964

[7] R.S.Khurmi And J.K.Gupta 'Machine Design' Eurasia Publishing House Pvt. Ltd., Second Edition, 1980

[8] R.K.Jain 'Machine Design' Khanna Publishers, Sixth Edition, 1991

[9] S.S.Bhavikatti 'Strength Of Materials', Vikas Publishing House Pvt. Ltd., Second Edition, 1999

[10] ermann Jutz And Eduard Scharkus 'Westermann Tables For The Metal Trade' Published By Wiley Eastern Limited, Third Edition, 1984

[11] http://www.lvsales.com/lvskymch.htm 
Deshpande et al : Product Re-designing and Development of Key Duplicating...

[12] http://www.keymart.com/key_machines.htm

[13] http://www.engineeringtalk.com/news/tce/ tce107.html

[14] http://www.jtsmach.com/jtswebshop/ asp/saws_index.asp

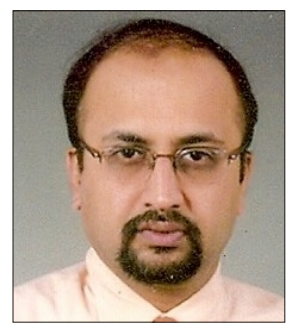

Dr. A. S. Deshpande is the Principal of Fr. C. Rodrigues College of Engineering, Bandra, Mumbai. A post-graduate from IIT Kanpur, he obtained his doctorate from NIT, Suratkal in the area of CAD / CAM. He has published 22 papers in Journals and Conferences and his

[15] http://www.thurstonmfg.com/pg_2.htm\#plainmet

[16] http://www.solidworks.com/pages/ products/edu/soli dworksforstudents.html

[17] http://www.ulrich-eppinger.net

[18] http://web.mit.edu/2.744/www/courseinfor mation/ classnotes.shtml experience in the field of academics and industry extends over a period of 23 years. 